\title{
Influência da escarificação e da temperatura sobre a germinação de sementes de Samanea tubulosa (Benth.) Barneby \& J.W. Grimes (sete cascas)
}

\author{
Roseli Muniz GIACHINI ${ }^{1}$, Francisco de Almeida LOBO $^{2}$, Maria Cristina de Figueiredo e ALBUQUERQUE ${ }^{3}$, \\ Carmen Eugenia Rodríguez ORTÍZ ${ }^{4}$
}

\begin{abstract}
RESUMO
Samanea tubulosa (Benth.) Barneby \& J.W Grimes (sete cascas) é uma planta arbórea nativa do Pantanal Matogrossense, cujas sementes possuem dormência provavelmente causada pela impermeabilidade do tegumento à água. O presente trabalho foi conduzido com o objetivo de comparar a eficiência da escarificaçáo mecânica e química para superar a dormência tegumentar e o efeito da temperatura sobre a germinação de sementes de sete cascas. Foram empregados quatro diferentes procedimentos de escarificação: testemunha (sem escarificação); a escarificação mecânica; a escarificação com ácido sulfúrico durante cinco minutos e a escarificação com ácido sulfúrico durante dez minutos. Os níveis de temperatura empregados foram de 20, 25, 30 e $35^{\circ} \mathrm{C}$. A semeadura foi realizada em papel toalha germitest, na forma de rolo. O delineamento experimental adotado foi o inteiramente casualizado com os tratamentos em esquema fatorial $4 \mathrm{x} 4$. Para cada tratamento, foram utilizadas quatro repetiçóes de 25 sementes. Foi avaliada a porcentagem de germinação das sementes, utilizado como critério emissão da raiz primária com $2 \mathrm{~mm}$ de comprimento. Foi observado que a espécie $S$. tubulosa possui dormência tegumentar causada pela impermeabilidade do tegumento a água. As escarificaçôes química com ácido sulfúrico por cinco e dez minutos foram eficientes para superação da dormência e as combinaçôes de escarificação com temperatura que promoveram maiores porcentagens de germinação para a espécie foram a escarificação com imersão em ácido sulfúrico durante cinco e dez minutos e as temperaturas de 25,30 e $35^{\circ} \mathrm{C}$.
\end{abstract}

PALAVRAS-CHAVE: Sementes florestais, pantanal, dormência.

\section{Influence of scarification and temperature on seed germination of Samanea tubulosa (Benth.) Barneby \& J.W. Grimes (seven shells)}

\section{ABSTRACT}

Samanea tubulosa (Benth.) Barneby \& JW Grimes (seven shells) is a tree plant native to the Mato Grosso Pantanal, whose seeds have dormancy probably caused by impregnability of its integument to water. This work was carried out to compare the efficiency of mechanical and chemical scarification for overcoming integumentary dormancy, and the effect of temperature on the germination of seeds of seven shells. We employed four different scarification procedures: those in control (without scarification); mechanical; with sulfuric acid for five minutes and with sulfuric acid for ten minutes. The temperature levels employed were $20,25,30$ and $35^{\circ} \mathrm{C}$. Seeding was done on paper tower germitest, in the form of roll. The experimental design was completely randomized to treatment in a factorial $4 \times 4$. For each treatment, using four replicates of 25 seeds, we evaluated the germination percentage of seeds, used as primary root issue with $2 \mathrm{~mm}$ in length. We observed that $S$. tubulosa has integumentary numbness caused by its impregnability to water. The chemical scarifications with sulfuric acid for five and ten minutes were efficient in breaking the dormancy; and the scarification combinations with temperatures that promoted the highest percentages of germination for the species were those with sulfuric acid for five to ten minutes, at temperatures of 25,30 and $35^{\circ} \mathrm{C}$.

KEYWORDS: Forest seeds, wetlands, dormancy.

\footnotetext{
1 Universidade Federal de Mato Grosso, UFMT, E-mail: roselimgmt@hotmail.com

2 Universidade Federal de Mato Grosso, UFMT, E-mail: f_a_lobo@yahoo.com.br

3 Universidade Federal de Mato Grosso, UFMT, E-mail: mariacfa@terra.com.br

${ }^{4}$ Universidade Federal de Mato Grosso, UFMT, E-mail: cerotiz@yahoo.com.br
} 


\section{INTRODUÇÃO}

O uso de leguminosas arbóreas ou arbustivas para recuperação de solos degradados e melhoria daqueles de baixa fertilidade natural, tem sido uma prática comum em regiôes tropicais, notadamente em áreas destinadas à produçấo de alimentos básicos. A família Mimosaceae (Leguminosae: Mimosoideae) abrange mais de 12 mil espécies espalhadas pelo mundo afora, e uma das principais características dessas plantas é o tipo do fruto, chamado comumente vagem (Ferreira Neto, 1994).

A espécie Samanea tubulosa (Benth.) Barneby \& J.W. Grimes, (sete casca), também conhecida como farinha-seca, abobreira, pau-de-cangalha, alfarobo, pertence à família Leguminosae (Mimosoideae), é uma árvore de grande porte podendo atingir de $4-18$ metros de altura e $25-45 \mathrm{~cm}$ de diâmetro. Folhas compostas bipinadas, num mesmo eixo, de $8-28 \mathrm{~cm}$. A inflorescência é em capítulos terminais, agrupados de 6-15, cada um com 12-20 flores, sobre pedúnculos de 4-10 $\mathrm{cm}$ de comprimento. Fruto do tipo vagem, séssil, indeiscente, de 10-18 cm de comprimento, com 20-30 sementes (Lorenzi, 2002). O tronco é mais ou menos ereto e revestido por casca grossa e com fissuras, fazendo jus ao nome vulgar sete cascas.

Ocorre no Mato Grosso do Sul, Mato Grosso - Pantanal Mato-grossense e Chapada dos Guimarães; sul do Pará, Baixo Amazonas e Bahia no vale do São Francisco. Também no Paraguai, Bolívia e Peru. É semelhante à Samanea inopinata (Harms), porém, essa ocorre mais comumente na mata hidrófila sul baiana. A árvore é ornamental e muito cultivada na arborização rural. Como ocorre em mata semidecídua do Pantanal e lá sendo uma regiâo de muitas fazendas criadoras de gado, a sua vagem é utilizada como forrageira. Sua madeira é empregada em marcenaria, moiróes e para lenha (Lorenzi, 2002).

Apesar da grande diversidade de espécies florestais nativas do Brasil, poucas estấo incluídas nas Regras para Análises de Sementes (RAS), e, para as sementes de $S$. tubulosa, ainda náo estấo estabelecidos os critérios para a realização do teste de germinação (Brasil, 1992).

O plantio de espécies nativas, com finalidade econômica ou conservacionista, exige um estudo ecológico e fisiológico de cada espécie, nesses estudos inclui-se a germinação das sementes, que é uma das etapas do seu desenvolvimento (Bello, 2005). A água, o oxigênio, a temperatura e para algumas espécies a luz são condiçôes básicas requeridas para a germinação das sementes (Fowler e Bianchetti, 2000). Portanto, os conhecimentos de como esses fatores ambientais influenciam na germinação, são muito importantes, assim, eles podem ser controlados e manipulados de forma a aperfeiçoar a germinação, diminuindo os gastos e obtendo assim mudas de qualidade para o plantio (IPEF, 1998). A germinação de sementes maduras, quando ocorre sob condiçóes ambientais adequadas, é entendida como sendo o processo de reativação do crescimento do embriáo, chegando ao ponto mais elevado, isto é o rompimento do tegumento (Fowler e Bianchetti, 2000).

A germinação é um fenômeno biológico que pode ser considerado pelos botânicos como a retomada do crescimento do embriáo, com o subseqüente rompimento do tegumento pela radícula. Entretanto, para os tecnólogos de sementes, a germinaçáo é definida como a emergência e o desenvolvimento das estruturas essenciais do embriáo, manifestando a sua capacidade para dar origem a uma plântula normal, sob condiçóes ambientais favoráveis (IPEF, 1998).

Algumas sementes possuem dormência, um dos principais problemas para produção de mudas de espécies florestais nativas, principalmente de leguminosas. A dormência de sementes é um processo caracterizado pelo atraso da germinação, quando as sementes, mesmo em condiçôes ambientais favoráveis (umidade, temperatura, luz e oxigênio), não germinam. Esse fenômeno pode durar poucos dias ou até meses, e se estender por vários anos (Cicero et al., 1986). Portanto, quando se depara com este fenômeno há necessidade de se conhecer como as espécies superam o estado de dormência, para que através dele seja possível buscar alternativas para uma germinação rápida e homogênea (IPEF, 1997).

Segundo Rolston (1978) citado por Nascimento et al., 2003) a impermeabilidade do tegumento à água é o mecanismo mais comum de dormência de sementes em leguminosas tropicais, ocorrendo com mais freqüência nas subfamílias Caesalpinoideae e Mimosoideae, segundo Duarte (1978) citado por Nascimento et al., ( 2003). A maioria das leguminosas apresenta alta porcentagem de sementes "duras", sendo essa dormência devido à presença de uma cobertura impermeável à água (Brasil, 1992), talvez, decorrente da camada de células em paliçada cujas paredes celulares são espessas e recobertas externamente por camada cuticular cerosa (Suñe e Franke, 2006).

Portanto, levando em consideraçáo importância ecológica da espécie $S$. tubulosa para recuperação de áreas degradadas e devido ao potencial da espécie como forrageira e arborização, este trabalho teve como objetivo comparar a eficiência da escarificação mecânica e química para superar a dormência tegumentar e o efeito da temperatura sobre a germinação das sementes de sete cascas.

\section{MATERIAL E MÉTODOS}

Foram utilizadas sementes de $S$. tubulosa obtidas de frutos recém caídos de uma árvore matriz do Parque Beripoconé, Poconé, Mato Grosso, em setembro de 2007. O trabalho foi desenvolvido no Laboratório de Sementes da Faculdade de 
Agronomia e Medicina Veterinária (FAMEV), vinculado à Universidade Federal de Mato Grosso (UFMT), em outubro de 2007.

Após a coleta, os frutos foram levados ao laboratório para retirada das sementes e essas foram embaladas em sacos de papel para serem armazenadas em câmaras resfriadas à temperatura de $18^{\circ} \mathrm{C}$ até o momento da instalação dos experimentos. Para evitar incidência de fungos as sementes de todos os tratamentos foram previamente tratadas com imersão em solução de hipoclorito de sódio $(2 \%)$ durante cinco minutos.

O experimento foi desenvolvido sob o delineamento inteiramente casualizado em esquema fatorial, com quatro repetiçóes de 25 sementes para cada tratamento. Os fatores estudados foram a escarificação e a temperatura. Foram empregados quatro diferentes procedimentos de escarificação, sendo estes a testemunha (sem escarificação), a escarificação mecânica, a escarificação com ácido sulfúrico durante cinco minutos e a escarificação com ácido sulfúrico durante dez minutos. Os níveis de temperatura empregados foram de 20 , 25,30 e $35^{\circ} \mathrm{C}$.

As sementes submetidas ao tratamento de escarificação mecânica foram colocadas num tambor giratório revestido com lixa acoplado a um motor de induçáo monofásico (Escarificador marca DE LEO), durante cinco segundos.

As sementes submetidas aos tratamentos com ácido foram submersas em solução de ácido sulfúrico ( $98 \%$ p.a.) durante o tempo específico para cada um dos tratamentos, ou seja, cinco ou dez minutos de imersão. Imediatamente após a imersão, para ambos os casos, as sementes foram lavadas em água corrente por dez minutos. $\mathrm{O}$ teste de germinação foi conduzido em papel toalha tipo Germitest ${ }^{\circ}$, na forma de rolos, umedecidos com volumes de água $(\mathrm{em} \mathrm{mL})$ equivalente a 2,5 vezes a massa do substrato(g), sem adiçáo posterior de água, com 3 folhas/rolo e acondicionadas em sacos plásticos transparentes de 0,04 $\mathrm{mm}$ de espessura.

Os rolos de papel com as sementes foram levados para câmaras de germinação do tipo B.O.D (Biochemical Oxigen Demand), com fotoperíodo artificial de 12 horas e fase luminosa de $10 \mu \mathrm{mol} . \mathrm{m}^{2} . \mathrm{s}^{1}$ de radiação PAR (radiação fotossinteticamente ativa). Quatro câmaras foram utilizadas simultaneamente e suas temperaturas fixadas em 20, 25, 30 e $35^{\circ} \mathrm{C}$. Em cada câmara foram acondicionadas as quatro repetiçóes de cada um dos tratamentos de escarificaçáo.

As avaliaçôes foram efetuadas diariamente após a instalação do teste, sendo calculada a porcentagem final de germinaçáo, usando como critério a emissão da radícula a partir de $2 \mathrm{~mm}$ de comprimento.

Os dados originais de germinaçâo foram submetidos aos testes de normalidade (Teste de Lilliefors) e homogeneidade de variâncias (Bartlle’s test). As médias foram comparadas pelo teste de Tukey a 5\% de probabilidade.

\section{RESULTADOS E DISCUSSÃO}

Os dados de germinação apresentaram normalidade e homogeneidade, náo apresentando necessidade de transformaçáo. Os resultados obtidos com as sementes de sete cascas indicaram que houve o efeito da escarificação, da temperatura e da interação entre estes fatores sobre a porcentagem de germinação, tendo em vista que foram obtidas altas taxas de germinação acima de $25^{\circ} \mathrm{C}$ com sementes escarificadas a cinco e dez minutos. As sementes não escarificadas germinaram em porcentagem média de 10,25\%, indicando que elas estavam dormentes (Tabela 1). Quando considerado o efeito principal da escarificação, os resultados apresentaram diferença significativa para os tratamentos com imersão das sementes em ácido sulfúrico durante cinco e dez minutos, comparados com escarificação mecânica e sem escarificação.

Tabela 1 - Valores médios dos dados de germinação \% obtidos por diferentes tratamentos de escarificação para superação de dormência sob diferentes temperaturas em sementes de $S$. tubulosa.

\begin{tabular}{lccccc}
\hline & \multicolumn{5}{c}{ Temperaturas } \\
Escarificação & $20^{\circ} \mathrm{C}$ & $25^{\circ} \mathrm{C}$ & $30^{\circ} \mathrm{C}$ & $35^{\circ} \mathrm{C}$ & Médias \\
\hline Testemunha & $10 \mathrm{Ba}$ & $9 \mathrm{Ba}$ & $13 \mathrm{Ca}$ & $9 \mathrm{Ba}$ & $10,25 \mathrm{C}$ \\
Mecânica & $27 \mathrm{BC}$ & $87 \mathrm{Aa}$ & $55 \mathrm{Bb}$ & $20 \mathrm{BC}$ & $47,25 \mathrm{~B}$ \\
$\mathrm{H}_{2} \mathrm{SO}_{4}-5$ & $71 \mathrm{Ab}$ & $77 \mathrm{Aab}$ & $89 \mathrm{Aa}$ & $92 \mathrm{Aa}$ & $82,25 \mathrm{~A}$ \\
minutos $\mathrm{H}_{2} \mathrm{SO}_{4}-10$ & $74 \mathrm{Ab}$ & $90 \mathrm{Aab}$ & $90 \mathrm{Aab}$ & $92 \mathrm{Aa}$ & $86,50 \mathrm{~A}$ \\
minutos & $45,50 \mathrm{C}$ & $65,75 \mathrm{~A}$ & $61,75 \mathrm{~A}$ & $53,25 \mathrm{~B}$ & \\
\hline Médias & & & & \\
\hline $\mathrm{F}$ Escarificação & $436,78^{* *}$ & & & & \\
\hline $\mathrm{F}$ Temperatura & $28,21^{* *}$ & & & & \\
\hline F Interação & $22,40^{* *}$ & & & & \\
\hline CV (\%) & 12,0 & & & & \\
\hline
\end{tabular}

** Significativo ao nível de $1 \%$

Médias seguidas da mesma letra maiúscula na coluna e minúscula na linha não diferem entre si pelo Teste de Tukey, ao nível de $5 \%$ de probabilidade.

Os tratamentos escarificadores mecânicos e químicos nas sementes de sete cascas favoreceram a superaçáo da dormência quando comparados a sementes sem tratamento (Tabela 1). Em sementes impermeáveis à água, a ação do ácido sulfúrico no enfraquecimento do tegumento pode ser resultado da remoção da cutícula e consequente exposição das camadas de macroesclereídes (Perez, 2004). Sementes de S. tubulosa necessitam de escarificação para superação de dormência (Lorenzi, 2002). 
Os resultados reforçam que o fator de dormência seja a impermeabilidade de tegumento. A impermeabilidade do tegumento é a causa mais comum da dormência de sementes de leguminosas (Popinigis, 1977). O ácido sulfúrico concentrado tem sido empregado para quebra de dormência de sementes de várias leguminosas. Para sete cascas, as sementes escarificadas com ácido sulfúrico não houve efeito significativo do período de escarificação na porcentagem de germinaçáo. Segundo Biruel et al.(2007), 10 minutos são suficientes para superar a dormência causada pela impermeabilidade do tegumento à água de sementes de pau-ferro. Lula et al. (2000), em experimento com sementes da espécie de Paspalum paniculatum L., concluíram que o tratamento mais eficiente para quebra de dormência foi com ácido sulfúrico concentrado P.A. (98\%) durante 20 minutos.

Segundo Barbosa et al.(1984) citado por Barbosa et al.(2004), sementes de visgueiro (Parkia pendula Benth) tratadas com ácido sulfúrico a 20 minutos e escarificação manual no tegumento, geralmente, apresentam índices elevados de germinação. Entretanto, Oliveira et al. (2003) verificaram que o ácido sulfúrico concentrado (98\%) por 15 minutos propiciou melhor porcentagem de germinaçẫo em Peltophorum dubium (Sprengel) Taubert, e com 30 minutos resultou entre 97 e $100 \%$ de mortes das sementes, pois o ácido sulfúrico, com seu alto grau de corrosão, danificou as sementes dessa espécie.

$\mathrm{Na}$ espécie Enterolobium contortisiliquum (Vell.) Morong (orelha-de-negro) o ácido a 90 minutos representa um bom resultado para superação da dormência (Ipef,1997), o que indica que, em função das características de resistência da testa das sementes de cada espécie, há um tratamento próprio que é mais eficaz. Apesar de tantos autores contatarem a eficiência do uso do ácido sulfúrico na superação de dormência de várias espécies, a prática exige cuidados, além de ser de difícil acesso aos produtores rurais.

Quando considerado o efeito principal da temperatura durante o processo germinativo, foi verificado, que as sementes submetidas a $25^{\circ} \mathrm{C} \mathrm{e} 30^{\circ} \mathrm{C}$ apresentaram maiores porcentagens de germinaçáo diferindo estatisticamente de $20^{\circ} \mathrm{C}$ e $35^{\circ} \mathrm{C}$ (Tabela 1).

Para a maioria das espécies tropicais e subtropicais, a faixa de temperatura boa para germinação é encontrada entre 20 e $30^{\circ} \mathrm{C}$ (Ramos et al., 2006). A máxima varia entre 35 e $40^{\circ} \mathrm{C}$, podendo a mínima chegar ao ponto de congelamento (IPEF, 1998). Altas temperaturas favorecem a deterioraçáo das sementes de algumas espécies, enquanto que para outras, essa alta é benéfica. Em temperaturas menores, a germinação poderá ser inibida ou simplesmente ser lenta (Cicero et al., 1986). Em experimento feito com Torresia acreana Ducke, Bello (2005) afirmou que a temperatura de $30^{\circ} \mathrm{C}$ foi a mais adequada para germinação dessa espécie.
Pela análise dos resultados obtidos, o efeito da temperatura sobre a germinação das sementes foi dependente do tipo de escarificação empregada e houve interação entre escarificação e temperatura. Para escarificação mecânica, a temperatura de $25^{\circ} \mathrm{C}$ foi a que teve melhor desempenho para a germinaçáo. A testemunha se mostrou insensível aos tratamentos térmicos, devido à permanência em seu estado latente de dormência (Tabela 1). O resultado sugeriu que a dormência está associada à impermeabilidade do tegumento, o que poderá ser comprovado em experimentos futuros, utilizando como método a imersão das sementes em água por algum período em minutos ou horas.

Machado et. al. (2002) concluíram que para germinação de ipê amarelo (Tabebuia serratifolia) a faixa ótima da temperatura está entre 25 e $35^{\circ} \mathrm{C}$ e a germinação foi mais rápida na temperatura próxima de $30^{\circ} \mathrm{C}$. Souza et. al.(2007) verificaram que a maior porcentagem de germinação de olho-de-pombo (Adenanthera pavonina) foi obtida com temperaturas constantes de 30 e $35^{\circ} \mathrm{C}$ independente do substrato.

As sementes tratadas com ácido sulfúrico a cinco e dez minutos apresentaram porcentagens de germinação acima de $77 \%$ quando submetidas às temperaturas 25,30 e $35^{\circ} \mathrm{C}$ (Figura 1), sendo esses os melhores tratamentos para superação de dormência da espécie. Porém, devido aos riscos e cuidados necessários com uso do ácido, em relação a $S$. tubulosa, pode-se indicar também para superação da dormência o tratamento com escarificaçáo mecânica a uma temperatura de $25^{\circ} \mathrm{C}$, pois esta não diferiu estatisticamente dos tratamentos com ácido sulfúrico a cinco e dez minutos, ficando a média da porcentagem de germinação entre 87 e 90\%.

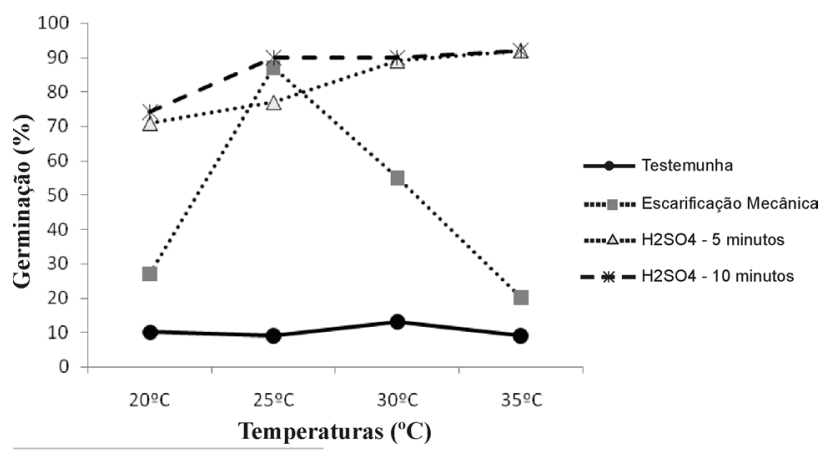

Figura 1 - Valores médios dos dados de germinação, obtidos por diferentes tratamentos e temperaturas para superação de dormência em sementes de S. tubulosa.

\section{CONCLUSÕES}

A espécie S. tubulosa possui dormência tegumentar causada pela impermeabilidade do tegumento à água.

A escarificação química com ácido sulfúrico cinco e dez minutos foi mais eficiente para superaçáo da dormência de S. tubulosa. 
Sementes sem tratamento para superação de dormência foram insensíveis aos tratamentos térmicos.

As combinações de escarificação com temperatura que promoveram maior porcentagem de germinaçáo em $S$. tubulosa foram a escarificaçáo com imersão em ácido sulfúrico durante cinco e dez minutos e as temperaturas de 25,30 e $35^{\circ} \mathrm{C}$.

A escarificação mecânica pode ser utilizada para superação de dormência de sete cascas.

Por ter havido danos nas sementes devido ao uso do tambor giratório, a escarificação mecânica poderá ser feita de forma manual, esfregando as sementes sobre uma superfície abrasiva. Entretanto, despenderá de maior tempo para escarificar as sementes manualmente.

\section{AGRADECIMENTOS}

Expressamos nossos sinceros agradecimentos a Engenheira Florestal Edmara Pereira da Silva pela ajuda na coleta dos dados.

\section{BIBLIOGRAFIA CITADA}

Barbosa, A.P.; Sampaio, P. de; T.B.; Campos, M.A.A.; Varela, V.P.; Gonçalves, C. de Q.B.; Iida, S. 2004. Tecnologia alternativa para a quebra de dormência das sementes de pau-de-balsa (Ochroma lagopus Sw., Bombacaceae). Acta Amazonica, 34: 107-110.

Brasil. Ministério da Agricultura e Reforma Agrária. 1992. Regras para análise de sementes. Brasília:CLAV/DNDV/SNAD/MA. $365 \mathrm{pp}$.

Bello, E.P. de B.C. 2005. Influencia de substratos, temperatura, estresse hídrico e armazenamento na germinação de Torresia acreana Ducke. Dissertação (Mestrado em Agricultura Tropical), Faculdade de Agronomia e Medicina Veterinária, Universidade Federal de Mato Grosso, Cuiabá. 93 pp.

Biruel, R.P.; Aguiar, I.B. de; Paula, R.C. 2007. Germinação de sementes de pau-ferro submetidas a diferentes condiçóes de armazenamento, escarificação química, temperatura e luz. Revista brasileira de sementes, 29: 134-141.

Cicero, S.M.; Julio, M.F.; Silva, W.R. da. 1986. Atualização em produção de sementes. In. I Semana de atualização em produção de sementes. Piracicaba. Resumos. Piracicaba, Sáo Paulo.

Ferreira Neto, P.S.F. 1994. Comportamento inicial do Eucalyptus grandis W. Hill ex Maiden em plantio consorciado com leguminosas na região do médio Rio Doce, Minas Gerais. Tese ((Magister Scientiae). Universidade Federal de Viçosa, UFV, Minas Gerais. $78 \mathrm{pp}$.

Fowler, J.A.P.; Bianchetti, A. 2000. Dormência em sementes florestais. Colombo: Embrapa Florestas, (Embrapa Florestas, Documentos, 40). $27 \mathrm{pp}$.
IPEF, 1998. Informativo sementes. (www.ipef.br/tecsementes/ germinacao.asp). Acesso em: 21/11/ 2007

IPEF, 1997. Informativo sementes. (www.ipef.br/tecsementes/ dormencia.asp). Acesso em: 21/11/2007

Lorenzi, H. 2002. Árvores Brasileiras: manual de identificação e cultivo de plantas arbóreas nativas do Brasil. Vol 2. Editora Plantarum, Odessa, SP, $201 \mathrm{pp}$.

Lula, A. de A.; Alvarenga, A.A. de; Almeida, L.P. de; Alves, J.D.; Magalhães, M. M. 2000. Estudos de agentes químicos na quebra da dormência de sementes de Paspalum paniculatum L. Revista Ciência Agrotecnica, 24: 358-366.

Machado, C.F.; Oliveira, J.A. de; Davide, A.C.; Guimarães, R.M. 2002. Metodologia para a condução do teste de germinação em sementes de Ipê-Amarelo (Tabebuia serratifolia (Vahl) Nicholson). Revista Cerne, 8: 17-25

Nascimento, W.M.O.; Ramos, N.P.; Carpi, V.A.F.; Filho, J.A.S.; Cruz, E.D. 2003. Temperatura e substrato para germinação de sementes de Parkia platycephala BENTH. (LeguminoseaeMimosoideae). In. Revista Agricultura Tropical, 7: 119-129.

Oliveira, L.M. de; Davide, A.C.; Carvalho, M.L.M. de. 2003. Avaliação de métodos para quebra da dormência e para a desinfestação de sementes de Canafístula (Peltophorum dubium. Revista Árvore, 27: 597-603.

Perez, S.C.J.A. 2004. Envoltórios, p.125-134. In: Ferreira, A.G.; Borghetti, F. (Org.). Germinaçấo: do básico ao aplicado. Porto Alegre: Artemed.

Popinigis, F. 1977. Dormência, p.75-79. In semente. Brasília, Agiplan. Fisiologia da

Ramos, M.B.P.; Varela, V.P.; Melo, M. de F.F. 2006. Influência da temperatura e da água sobre a germinação de sementes de Paricá (Schizolobium amazonicum Huber ex Ducke LeguminosaeCaesalpinioideae). Revista Brasileira de Sementes, 28: 163-168.

Souza, E.B. de; Pacheco, M.V.; Matos, V.P.; Ferreira, R.L. C. 2007. Germinação de sementes de Adenanthera pavonina L. em função de diferentes temperaturas e substratos. Revista Árvore, 31: $437-443$.

Suñe, A.D.; Franke, L.B. 2006. Superação de dormência e metodologias para testes de germinaçáo em sementes de Trifolium riograndense Burkart e Desmanthus depressus Humb. Revista Brasileira de Sementes, 28: 29-36.

Recebido em: 29/10/2008

Aceito em: 20/04/2009 
